\title{
Polyphenol-Rich Olive Mill Wastewater Extract and Its Potential Use in Hair Care Products
}

\author{
Lisa-Marie Sittek*, Thomas M. Schmidts, Peggy Schlupp \\ RSC Pharma GmbH \& Co. KG, Giessen, Germany \\ Email: *sittek@rscpharma.com
}

How to cite this paper: Sittek, L.-M., Schmidts, T.M. and Schlupp, P. (2021) Polyphenol-Rich Olive Mill Wastewater Extract and Its Potential Use in Hair Care Products. Journal of Cosmetics, Dermatological Sciences and Applications, 11, 356-370. https://doi.org/10.4236/jcdsa.2021.114029

Received: November 11, 2021

Accepted: December 13, 2021

Published: December 16, 2021

Copyright $\odot 2021$ by author(s) and Scientific Research Publishing Inc. This work is licensed under the Creative Commons Attribution International License (CC BY 4.0).

http://creativecommons.org/licenses/by/4.0/

\begin{abstract}
In this work, the influence of phenol-enriched olive mill wastewater (OMWW) extract on hair growth was investigated in vitro on human follicle dermal papilla cells. OMWW has already shown great potential for use in skincare products, and its high polyphenol content is predestined to have a positive effect on hair growth. The studies included caffeine, a positive modulator of hair growth, and dihydrotestosterone, which causes hair loss in vivo, as controls. The impact of the investigated compounds on hair growth was evaluated by studies on cell viability and proliferation, the release of growth factors (insulin-like growth factor-1 and vascular endothelial growth factor), and the reduction of reactive oxygen species formation. OMWW showed a positive influence on the proliferation of the human follicle dermal papilla cells. Moreover, the extract leads to a significantly increased secretion of insulin-like growth factor-1, and a considerable reduction in reactive oxygen species formation was observed. Overall, our results show that the investigated phenol-enriched OMWW extract is a promising ingredient for hair care to improve hair growth, prevent hair loss due to oxidative stress and maintain a healthy scalp.
\end{abstract}

\section{Keywords}

Hair Growth, Hair Loss, Human Follicle Dermal Papilla Cells, Caffeine, Dihydrotestosterone, IGF-1, VEGF, Reactive Oxygen Species

\section{Introduction}

Besides its protective function against heat, UV radiation, and exposure to cold, the human scalp hair also has an important psychological role. The hair im- 
mensely shapes the external appearance and contributes decisively to self-esteem. As a consequence, hair growth disorders and hair loss can significantly affect the well-being and quality of life of those affected and contributes to negative selfesteem as well as an increased prevalence of psychosocial problems [1] [2].

Hair consists essentially of keratin and is embedded with its root in the scalp. The hair root is anchored in the epidermis and enclosed by the hair follicle. This follicle consists of an epithelial and a dermal (mesenchymal) component, whose interactions play an essential role regarding the regulation of hair follicle growth [3]. On average, the scalp hair grows $0.3-0.5 \mathrm{~mm}$ per day, which is about $15 \mathrm{~cm}$ in a year [4]. The resulting hair length is essentially determined by the growth rate and the duration of sustained growth. Hair growth is subject to a fixed cycle consisting of several phases of varying periods. This cycle is divided into the anagen, catagen, and telogen phases [5]. In contrast to many animals, the hair cycles of the individual hair follicles run asynchronously in humans [6]. The anagen phase is the growth phase where a new hair root is formed and hair production begins. This phase is characterized by increased cell proliferation and lasts for $2-8$ years, depending on age, sex, and growth site [7] [8]. It is followed by the catagen phase, which lasts several weeks and is defined by an apoptosis-controlled regression of the cells and reduced cell proliferation. That leads to controlled degeneration of the hair follicle, causing it to tighten, and the connection between the hair and the hair root is lost [9]. The hair then enters a resting phase (telogen) lasting 2 - 4 months, during which the loose hair is detached from the scalp by mechanical influences or pushed out of the follicle by the new, regrowing hair [9]. Due to the cyclic growth phases, no hair grows indefinitely and remains in the anagen phase. Instead, it may enter the catagen stage according to a fixed rhythm controlled by numerous complex physiological and pathological factors.

The dermal papilla at the base of the hair follicle is crucial for hair follicle morphogenesis and cycling [10]. Dermal papilla cells release growth factors that induce epithelial cells to proliferate, leading to hair shaft growth and acceleration of hair regeneration [11]. They secrete numerous growth factors such as insulin-like growth factor-1 (IGF-1) and vascular endothelial growth factor (VEGF), which are necessary for maintaining the anagen phase, cell proliferation, and migration [12] [13] [14].

Since the hair continuously enters the telogen phase, a person loses about 70 100 hairs per day. This natural hair loss is usually not noticeable on the head, as the new hair grows back at the same time. In case of damage to the hair root or follicle in the growth phase, nutrients deficiency, mechanical stress, hormonal imbalances, or if many hairs enter the telogen phase at once, it leads to increased hair loss (alopecia) and thinning of the hair [15] [16]. As both men and women are affected by increased hair loss and thinning hair, especially with age, there is an urgent need to develop new approaches and products that support hair growth, strengthen hair and prevent hair loss [17] [18] [19].

Olive mill wastewater (OMWW) is a phenol-rich by-product of olive oil pro- 
duction with great potential for use in skincare to improve skin health and protection and with beneficial effects on skin aging [20]. Since studies of polyphenols from green tea and Annurca Apples showed a beneficial effect on hair growth, the influence of OMWW extract on human follicle dermal papilla cells (HFDPC) and their secretion of growth factors (IGF-1 and VEGF) was investigated in this work [21] [22]. In addition, the protective function of the extract regarding the formation of reactive oxygen species (ROS) in the cells was examined.

\section{Materials and Methods}

\subsection{Olive Mill Wastewater Extract and Sample Preparation}

The olive mill wastewater used for this study was provided by Agriturismo La Vialla (Castiglion Fibocchi (Arezzo), Italy). The phenol-enriched purified extract (OMWW extract, quantitative composition [20]) was obtained from Massimo and Daniele Pizzichini according to the Patent formulation (Patent 8815815) [23]. Before use, the OMWW extract was sonicated for $10 \mathrm{~min}$, centrifuged at $500 \mathrm{x} \mathrm{g}$ for $20 \mathrm{~s}$, and filtrated $(0.2 \mu \mathrm{m})$. Final dilutions were prepared with cell growth medium. Besides, the effects of caffeine (Caesar \& Loretz GmbH, Hilden, Germany) and dihydrotestosterone (Sigma-Aldrich, St. Louis, MO, USA) on cells were also investigated. For this purpose, a caffeine stock solution with a concentration of $10 \mathrm{mg} / \mathrm{mL}$ was prepared in phosphate-buffered saline (PBS) and filtered $(0.2 \mu \mathrm{m})$. The final dilution of $0.25 \mathrm{mM}$ caffeine was prepared in cell growth medium. For dihydrotestosterone (DHT), a $10 \mathrm{mM}$ stock solution was prepared in ethanol and then diluted to $0.1 \mathrm{mM}$ in cell growth medium.

\subsection{Cultivation of Human Follicle Dermal Papilla Cells}

Human follicle dermal papilla cells (HFDPC) obtained from PromoCell (Heidelberg, Germany) were cultured at $37^{\circ} \mathrm{C}$ and $5 \% \mathrm{CO}_{2}$ in follicle dermal papilla cell growth medium (PromoCell, Heidelberg, Germany) supplemented with 100 units $/ \mathrm{mL}$ penicillin and $100 \mu \mathrm{g} / \mathrm{mL}$ streptomycin (Capricorn Scientific, Ebsdorfergrund, Germany).

\subsection{Cell Viability Assay}

The effect of the samples on the viability of the HFDPCs was determined by MTT assay in accordance with Mosmann [24]. HFDPCs were seeded in 96-well plates (2500 cells per well) and incubated overnight at $37^{\circ} \mathrm{C}$ and $5 \% \mathrm{CO}_{2}$. Then the cells were washed with PBS and treated with the samples for $24 \mathrm{~h}(100 \mu \mathrm{L})$ and $48 \mathrm{~h}(200 \mu \mathrm{L})$. After sample incubation, $0.25 \mathrm{mg} / \mathrm{mL}$ MTT in cell growth medium was added, and the plate was incubated at $37^{\circ} \mathrm{C}$ for 4 hours. Subsequently, the MTT solution was removed, and the cells were lysed with dimethyl sulfoxide (Merck KgaA, Darmstadt, Germany) while shaking at $300 \mathrm{rpm}$ for 1 hour. Finally, the absorbance was measured at $570 \mathrm{~nm}$ and $650 \mathrm{~nm}$ (reference wavelength) using Synergy ${ }^{\mathrm{TM}}$ HTX multi-mode microplate reader with the soft- 
ware Gen5 $5^{\mathrm{TM}} 2.07$ (BioTek Instruments Inc., Winooski, VT, USA). Results are shown in relation to the untreated control (incubated with cell culture medium or incubated with $1 \%$ ethanol in medium), and dimethyl sulfoxide served as blank value. All experiments were performed three times with at least four replicates. HFDPCs from passages 3 to 6 were used. Statistical analyses were performed on results as described in Section 2.6 Statistical Analysis.

\subsection{ELISA of Growth Factors IGF-1 and VEGF}

HFDPCs (passages 5 to 8 ) were cultured in 48 -well plates (2500 cells per well) in $1 \mathrm{~mL}$ growth medium for four days at $37^{\circ} \mathrm{C}$ and $5 \% \mathrm{CO}_{2}$. Then the cells were washed with PBS and treated with the samples for $24 \mathrm{~h}(0.5 \mathrm{~mL})$ and $48 \mathrm{~h}(1$ $\mathrm{mL})$. Cell-free supernatants were collected, and the concentrations of Insulin-like growth factor 1 (IGF-1) and Vascular Endothelial Growth Factor (VEGF) were determined using commercial ELISA kits using the manufacture's protocols without adaptions (R\&D Systems Inc. Minneapolis, MN, USA). The absorbance was measured at $450 \mathrm{~nm}$ and $570 \mathrm{~nm}$ (reference wavelength) using Synergy $^{\text {TM }}$ HTX multi-mode microplate reader with the software Gen $5^{\mathrm{TM}} 2.07$ (BioTek Instruments Inc., Winooski, USA). Results are shown in relation to the untreated control. All experiments were performed three times with at least two replicates.

\subsection{Reactive Oxygen Species Assay in Vitro}

10,000 HFDPCs (passage 5 to 7) per well, in growth medium without phenol red (PromoCell, Heidelberg, Germany), were seeded in a black 96-well plate with a clear bottom (Corning Life Science, Tewksbury, MA, USA) and incubated overnight at $37^{\circ} \mathrm{C}$ and $5 \% \mathrm{CO}_{2}$. Cells were then washed twice with PBS, and $100 \mu \mathrm{L}$ of the samples containing $50 \mu \mathrm{M}$ 2,7-dichlorodihydrofluorescein diacetate (DCFH-DA, Sigma-Aldrich, St. Louis, MO, USA) were added. That was followed by incubation at $37^{\circ} \mathrm{C}$ for $30 \mathrm{~min}$ before the cells were washed again, and $100 \mu \mathrm{L}$ of $100 \mu \mathrm{M} \mathrm{H}_{2} \mathrm{O}_{2}$ (Sigma-Aldrich, St. Louis, MO, USA) was applied. After incubation at $37^{\circ} \mathrm{C}$ and $5 \% \mathrm{CO}_{2}$ for $45 \mathrm{~min}$, a final washing step with PBS was carried out before measuring the fluorescence intensity (FLU, ex./em. 485/528 nm) using the microplate reader ( $100 \mu \mathrm{L}$ of phosphate buffer, bottom read). The DCFH radical scavenging activity was calculated based on Equation (1). All experiments were performed three times with at least four replicates.

$$
\text { DCHF radical scavenging activity }(\%)=100 \times \frac{\mathrm{FLU}_{\text {control }}-\mathrm{FLU}_{\text {sample }}}{\mathrm{FLU}_{\text {control }}}
$$

\subsection{Statistical Analysis}

Data are given as arithmetic mean values \pm standard deviation. To verify statistically significant differences between the mean values of different groups, a two-way ANOVA, followed by a Dunnett test, was carried out. Thus, $\mathrm{p} \leq 0.05$ is considered to indicate a significant difference. Statistical analysis was performed 
using GraphPad Prism ${ }^{\circledR}$ v8.3.0 (538) (San Diego, CA, USA).

\section{Results}

\subsection{Influence of OMWW Extract on the Viability of HFDPCs}

First, the influence of the OMWW extract in different dilutions, $0.25 \mathrm{mM}$ caffeine, and $0.1 \mathrm{mM}$ dihydrotestosterone, on HFDPC viability was examined via MTT assay over $24 \mathrm{~h}$ and $48 \mathrm{~h}$ to identify which dilutions are suitable for the following in vitro experiments and to determine whether the samples affect cell proliferation. After a 24 h-incubation with OMWW 1:100, the HFDPC showed viability of $6.3 \% \pm 1.56 \%$, and after $48 \mathrm{~h} 3.14 \% \pm 0.05 \%$ (Figure 1 ). In addition, a decrease in cell viability was observed after incubation with OMWW 1:200 (24 h $16.80 \% \pm 8.01 \%, 48$ h $2.35 \% \pm 0.18 \%)$ and OMWW 1:250 (24 h $68.22 \% \pm$ $11.80 \%, 48$ h $3.82 \% \pm 1.41 \%)$. Cells treated with OMWW 1:500 showed a significant increase in viability of $124.90 \% \pm 2.71 \%$ compared to the untreated control after $24 \mathrm{~h}$. This effect was not visible with $48 \mathrm{~h}$ incubation $(108.58 \% \pm 7.69 \%)$. Treatment of cells with $0.25 \mathrm{mM}$ caffeine for $24 \mathrm{~h}$ also resulted in a slightly increased cell viability of $110.21 \% \pm 4.90 \%$. This effect was not visible at $48 \mathrm{~h}$ incubation. The remaining samples (OMWW 1:750 and 0.1 mM DHT) showed no significant effect on cell viability (Figure 1). Based on these results, OMWW 1:500, OMWW 1:750, $0.25 \mathrm{mM}$ caffeine, and 0.1 mM DHT samples were chosen for further in vitro studies.

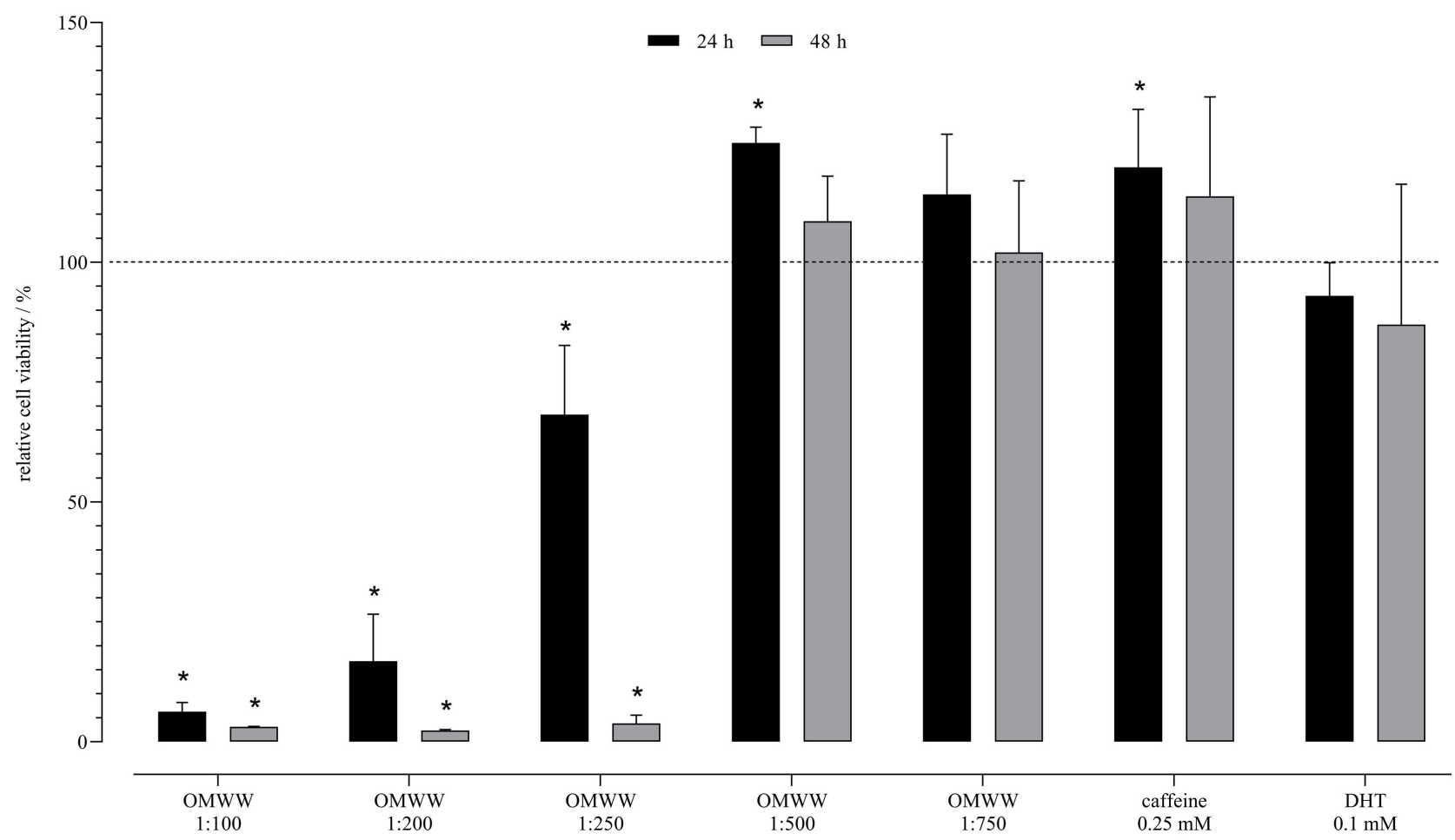

Figure 1. Viability of HFDPC (2500 cells per well, 96-well plate) after treatment with OMWW extract dilutions, $0.25 \mathrm{mM}$ caffeine, and $0.1 \mathrm{mM}$ dihydrotestosterone for $24 \mathrm{~h}$ and $48 \mathrm{~h}$, mean \pm standard deviation of three independent test runs with four repetitions, ${ }^{*} \mathrm{p} \leq 0.05$. Results are shown in relation to the untreated control ( $100 \%$ viability). 


\subsection{OMWW Extract Increases the Release of the Growth Factor IGF-1 from HFDPCs}

Since various studies show that growth factors and cytokines released by dermal papilla cells are essential for the division, proliferation, and differentiation of cells in the hair follicle and thus for hair growth, the influence of OMWW extract release of the growth factors IGF-1 and VEGF from HFDPC was investigated in this work. While incubation of the cells with both OMWW extract dilutions had no significant effect on the secretion of IGF-1 after $24 \mathrm{~h}$, incubation for $48 \mathrm{~h}$ resulted in a significant increase of IGF-1 in the supernatant for cells treated with OMWW 1:500 (346.67\% $\pm 55.72 \%)$ and OMWW 1:750 (290.39\% \pm $50.33 \%$ ) (Figure 2). Similar observations were made during incubation with caffeine. While treatment of the cells for $24 \mathrm{~h}$ resulted in a slight increase in IGF-1 $(149.68 \% \pm 20.88 \%)$, a 48 -hour incubation caused a significant increase of IGF-1 $(535.84 \% \pm 117.55 \%)$. The supernatant of dihydrotestosterone-treated HFDPC contained $146.59 \% \pm 9.46 \%(24 \mathrm{~h})$ respectively and $203.44 \% \pm 79.57 \%$ (48 h) IGF-1 in relation to the untreated control.

The secretion of the growth factor VEGF was not significantly affected by the samples after $24 \mathrm{~h}$ of incubation (Figure 3). Moreover, treatment with OMWW 1:500, OMWW 1:750, and caffeine for $48 \mathrm{~h}$ resulted in a slight decrease in VEGF release to $69.45 \% \pm 2.47 \%, 78.90 \% \pm 2.33 \%$, and $81.37 \% \pm 2.48 \%$ respectively.

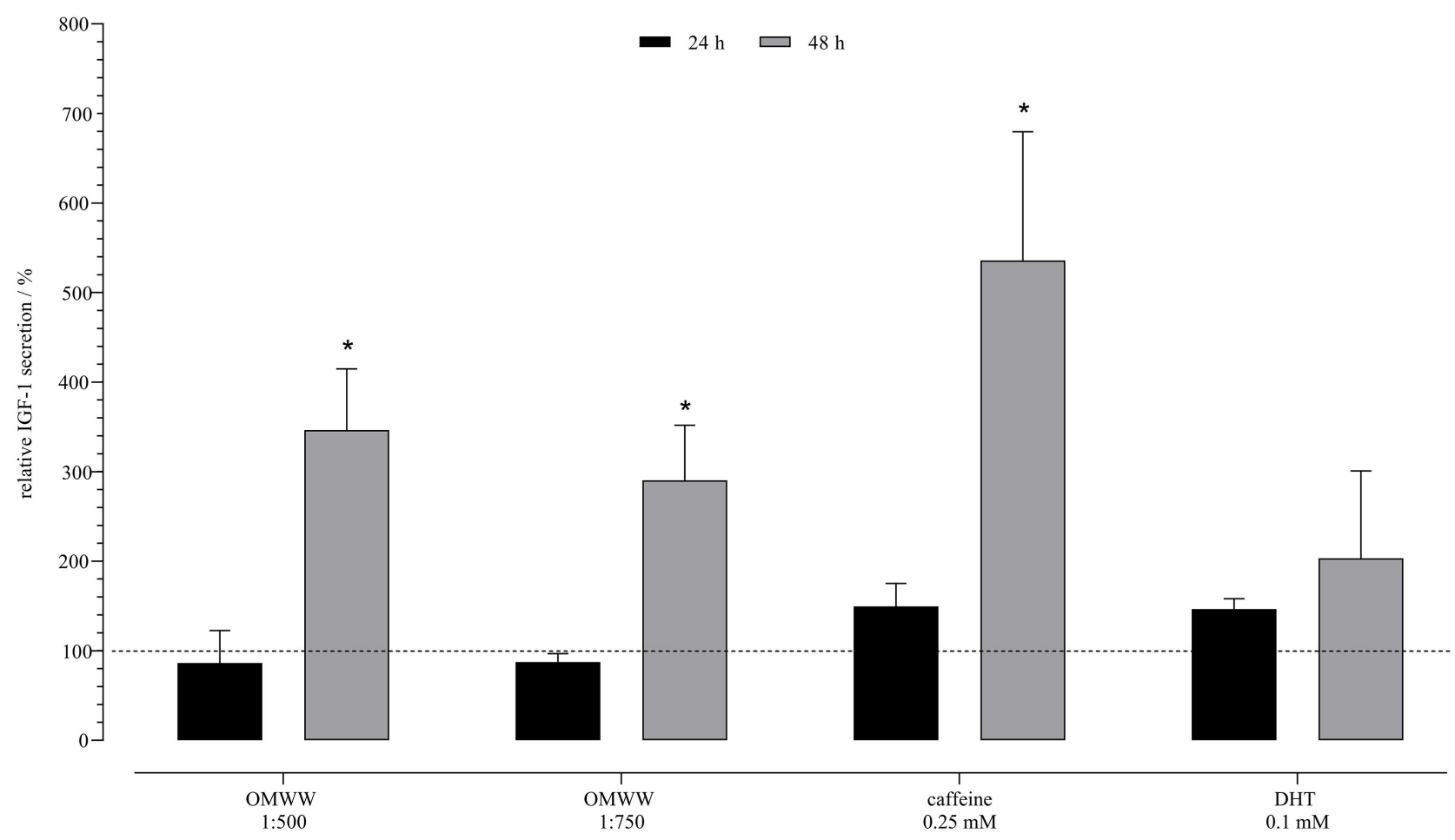

Figure 2. Relative IGF-1 secretion (untreated control 100\%) in cell-free supernatants after treatment with OMWW 1:500, OMWW 1:750, $0.25 \mathrm{mM}$ caffeine, and $0.1 \mathrm{mM}$ dihydrotestosterone for $24 \mathrm{~h}$ and $48 \mathrm{~h}$ measured by ELISA, mean \pm standard deviation of three independent test runs with two repetitions, ${ }^{\star} \mathrm{p} \leq 0.05$. 


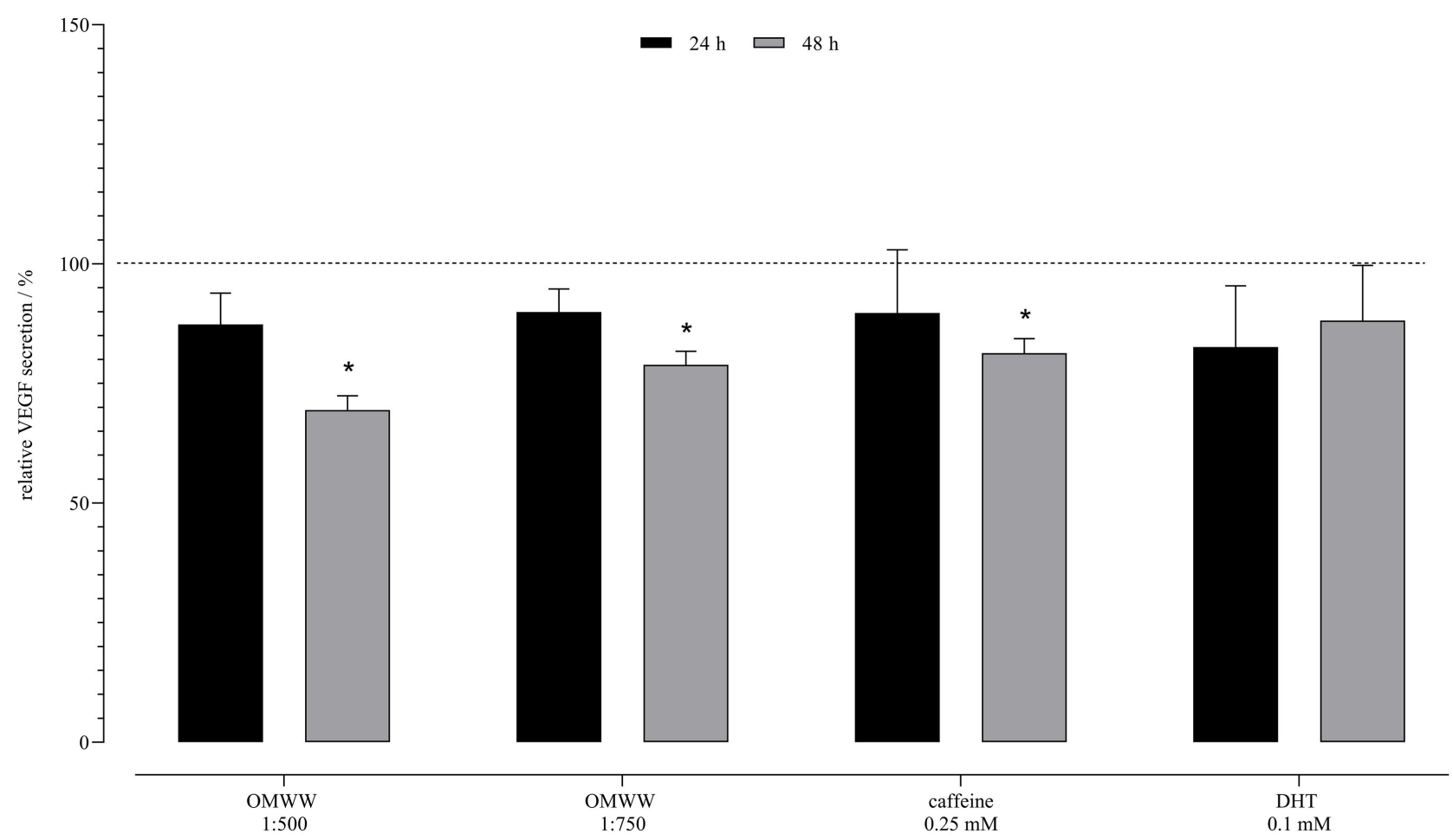

Figure 3. Relative VEGF secretion (untreated control 100\%) in cell-free supernatants after treatment with OMWW 1:500, OMWW 1:750, $0.25 \mathrm{mM}$ caffeine, and $0.1 \mathrm{mM}$ dihydrotestosterone for $24 \mathrm{~h}$ and $48 \mathrm{~h}$ measured by ELISA, mean \pm standard deviation of three independent test runs with two repetitions, ${ }^{\star} \mathrm{p} \leq 0.05$.

\subsection{OMWW Extract Reduces the Production of Reactive Oxygen Species in vitro}

To evaluate the antioxidant potential of the samples on human follicle dermal papilla cells, the formation of reactive oxygen species (ROS) was triggered by exposure of the cells to $\mathrm{H}_{2} \mathrm{O}_{2}$. HFDPC were incubated with the samples for 30 min before exposure to $\mathrm{H}_{2} \mathrm{O}_{2}$ to investigate the ability of the samples to reduce the formation of ROS. Due to studies by Rossi et al. [23] and Schlupp et al. [20], the OMWW extract was used diluted 1:500, 1:750, and additionally, the dilution 1:250 was tested. The ROS production was significantly reduced by the OMWW dilutions in a concentration-dependent manner (Figure 4). Thus, OMWW $1: 250,1: 500$ and $1: 750$ lead to a reduction of free radicals by $60.76 \% \pm 5.29 \%$, $47.40 \% \pm 6.20 \%$ and $24.10 \% \pm 2.01 \%$ respectively. While caffeine showed no significant DCFH radical scavenging activity $(-15.30 \% \pm 10.51 \%)$, incubation with DHT increased ROS production by $72.36 \% \pm 15.83 \%$.

\section{Discussion}

In this work, the potential of the phenol-rich olive mill wastewater extract was investigated, concerning the support of hair growth and the possible reduction as well as prevention of hair loss in vitro. Primary human follicle dermal papilla cells were used as a screening model for the experiments. These are specialized mesenchymal cells that play a major role in hair morphogenesis and regeneration by 


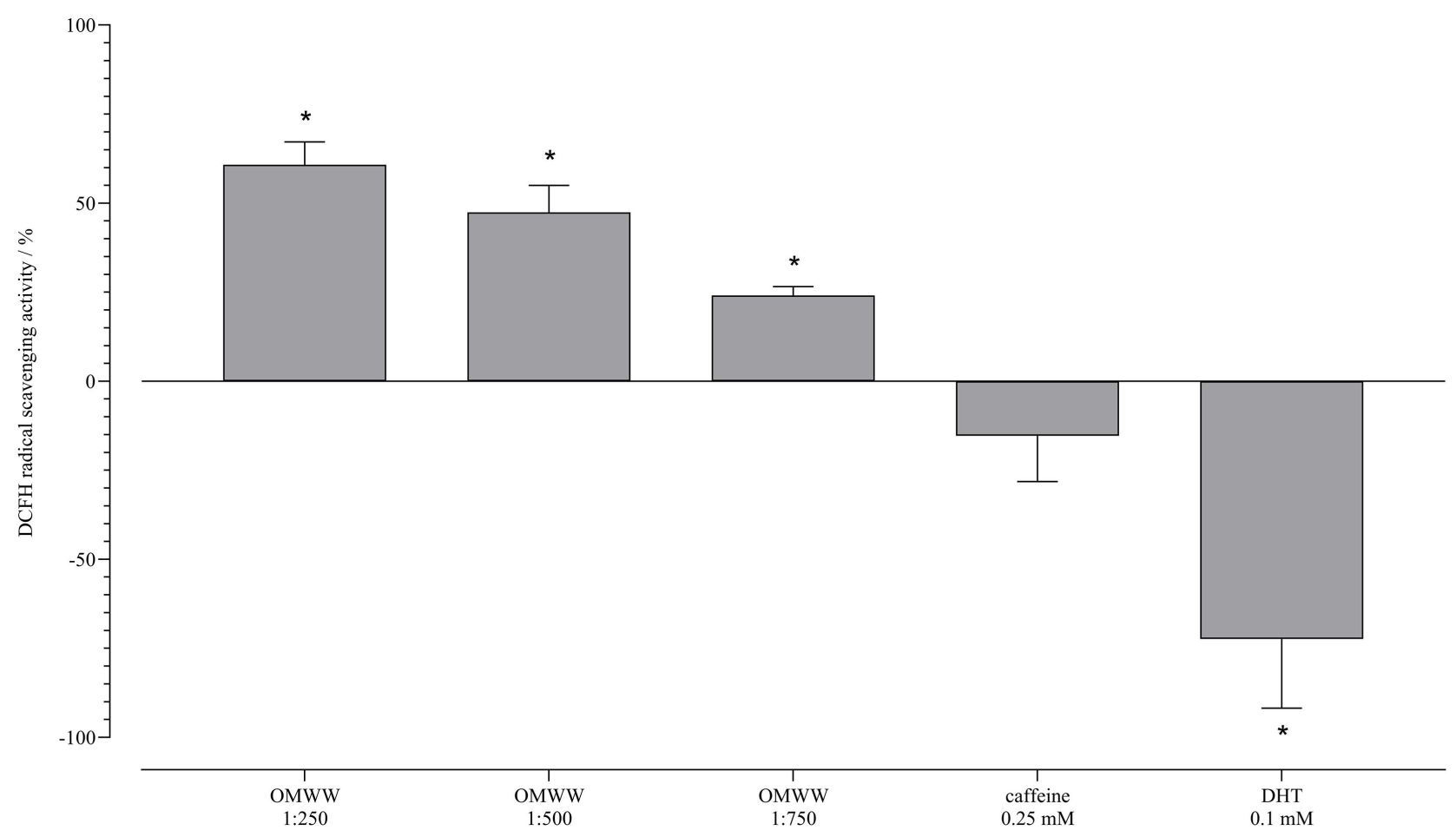

Figure 4. Relative DCFH radical scavenging activity (untreated control 100\%) in vitro. Treatment (30 min) of HFDPC with

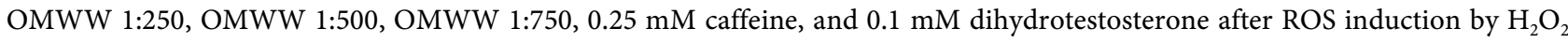
$(100 \mu \mathrm{M})$ for $45 \mathrm{~min}$, mean \pm standard deviation of three independent test runs with four repetitions, ${ }^{*} \mathrm{p} \leq 0.05$.

influencing follicle development and growth through the supply of multipotent stem cells, nutrients and growth factors [25] [26]. Due to their essential role in hair growth, HFDPC has been used in numerous studies as an in vitro screening model for the evaluation of various hair growth modulators [27]. To validate the experiments and to include suitable positive and negative reference substances, caffeine and dihydrotestosterone (DHT) were also tested. DHT is an activated form of testosterone resulting from systemic and local metabolism in the scalp, which leads to androgenic alopecia in men by shortening the hair follicle growth phase [28]. It is a known inhibitor of human hair follicle proliferation and induces apoptosis in HFDPC [29]. Our applied concentration of $0.1 \mathrm{mM} \mathrm{DHT}$ is based on studies by Lee et al. [30] and Shin et al. [31], who investigated the effect of DHT on human dermal papilla cells. Caffeine was chosen as a reference for this work because it is commonly used in hair care products and is claimed to stimulate hair growth and prevent hair loss. Fischer et al. showed that caffeine leads to a significant stimulation of hair follicle growth, reduces the negative influence of testosterone [32], and increases IGF-1 protein expression in male and female hair follicles in vitro [33]. In addition, the substance decreases the activity of the enzyme 5-reductase, which is responsible for the conversion of testosterone into dihydrotestosterone [34]. Following the studies of Fischer et al., we used caffeine with a concentration of $0.25 \mathrm{mM}$ (equivalent to $0.005 \%$ ).

The cell viability studies (Figure 1) indicate that caffeine has a slightly proliferative effect at $24 \mathrm{~h}$ incubation time. Zhuang et al. [35] also demonstrated that 
caffeine has a proliferative effect on HFDPC. In our experiments, OMWW at a dilution of 1:500 also showed a positive influence on cell proliferation that was slightly stronger than the proliferative effect of caffeine. Since proliferation is one of the most tested markers of HFDPC activity and the cells are critical for hair growth in the anagen phase of the hair cycle [36], the results imply that OMWW extract may positively influence hair growth by increasing the proliferation of follicle dermal papilla cells. Treatment of HFDPC with other polyphenol-rich extracts like Ecklonia cava and Annurca apple extracts led to increased cell proliferation as well [22] [37]. In addition, Schlupp et al. [20] showed that OMWW extract was also beneficial for skin cell viability. In contrast to the study by Kiesewetter et al. [38], no inhibitory effect of DHT on cell proliferation could be detected in our studies, whereby a higher concentration $(0.1 \mathrm{mM})$ was used in our experiments.

Considering that growth factors released by dermal papilla cells such as insulin-like growth factor-1 (IGF-1), fibroblast growth factor-5, vascular endothelial growth factor (VEGF), and platelet-derived growth factor have already been identified as essential mediators of hair growth by controlling processes such as division, proliferation, and differentiation of cells in the hair follicle, the influence of OMWW extract release of the growth factors IGF-1 and VEGF from HFDPC was investigated in this work [39] [40] [41]. Numerous studies, such as those by Rajendran et al. [12], showed that IGF-1 is produced and secreted by dermal papilla cells in vitro, which was confirmed by our experiments (Figure 2). A significantly increased secretion could be detected after 48 hours of treatment with OMWW 1:500, OMWW 1:750, and caffeine. IGF-1 is an insulin-like essential growth factor in many biological systems [42]. Regarding hair growth, IGF-1 plays a crucial role in regulating hair follicle development, maintaining the anagen phase, and is considered one of the key mediators of hair growth [14] [43] [44]. An in vivo study by Zhao et al. [45] demonstrated by systemic and local injection of IGF-1 that the growth factor is essential for the maintenance of hair growth and prevents hair follicles from prematurely entering the catagen phase. The study by Shin et al. showed that increased IGF-1 secretion in vitro in HFDPC also has positive effects on hair growth ex vivo [37]. Thus, treatment with the phenolic extract of Ecklonia cava resulted not only in an increased secretion of IGF-1 in vitro but also in an elongation of human hair shaft length $e x$ vivo. Regarding DHT, no significant effect on the release of IGF-1 was observed (Figure 2). Nevertheless, an in vivo study by Zhao et al. [46] showed that DHT administration in mice resulted in decreased IGF-1 expression, associated with a reduction in proliferating cells in hair follicles and inhibition of hair regrowth. Since our data show that DHT has no direct effect on the secretion of IGF-1 in HFDPC in vitro, the association of the parameters DHT, IGF-1 and hair loss in vivo seem to be more complex. Further investigations are required in vitro to determine the exact mechanism of action and connection. Another frequently investigated growth factor secreted by HFDPCs in vitro and in vivo is the vascular endothelial growth factor (VEGF), which stimulates vasculogenesis and an- 
giogenesis [47]. Concerning hair growth, several studies have shown that VEGF can promote hair growth, increase follicle size and hair thickness [41] [48] [49]. Incubation of HFDPCs with the samples for 24 hours did not result in any significant change regarding VEGF release (Figure 3). After 48 h, OMWW 1:500, OMWW 1:750, and caffeine lead to a significant reduction of VEGF secretion, whereas DHT does not influence the growth factor. Investigations by Kim et al. [50] indicated that a $48 \mathrm{~h}$ incubation of dermal papilla cells with 20 ppm caffeine leads to a significant increase of VEGF. Despite the higher applied concentration of caffeine, we could not confirm this in our experiments. In general, it should be noted that the study of DHT in our experiments did not show a significant effect on the release of growth factors in vitro, implying that the relationship of DHT and hair loss in vivo must have a much more complex mechanism. The entire process of hair growth is very intricate and not yet fully understood. It is known that the growth factors studied have a positive influence on hair growth, but the detailed mechanisms of action have not yet been unraveled. Therefore, more in vitro data need to be collected on this topic. Overall, based on the existing literature and our in vitro studies, it can be suggested that both OMWW extract and caffeine may have a positive effect on the anagen phase and thus on hair growth due to their positive impact on the release of the growth factor IGF-1.

Oxidative stress is associated with inflammatory processes, UV radiation, and cellular aging. Increased oxidative stress contributes to damage of cellular DNA, proteins, and lipids, which may lead to cell cycle arrest, cell senescence, and cell death [51]. This stress can also have a major impact on hair growth and balding. For example, Upton et al. [52] showed that oxidative stress promotes the secretion of TGF- $\beta 1$ in dermal papilla cells, an inhibitor of hair growth, and suppresses the release of the important growth factor IGF-1. In our study, the $\mathrm{H}_{2} \mathrm{O}_{2}$ induced ROS production was significantly reduced in a concentration-dependent manner by OMWW extract (Figure 4). This antioxidant potential and concentration dependence were also demonstrated in the studies by Schlupp et al. in dermal cells [20] and Rossi et al. in endothelial cells [23]. That shows the clear advantage of OMWW extract over caffeine in terms of the potential use in hair care products. Although caffeine showed similar positive effects as OMWW in the other experiments, caffeine has no beneficial effect on ROS formation. Dihydrotestosterone led to a significant increase in ROS production. That is consistent with literature data showing that DHT increases intracellular ROS levels and thereby induces cell death and senescence [30] [53]. Other antioxidants, such as ascorbic acid, were shown to stimulate the growth of HFDPCs and promote hair shaft elongation in vitro and in vivo [54]. Thus, OMWW can protect the essential hair follicle cells from oxidative stress or DHT and reduce ROSinduced hair loss through its antioxidant properties.

\section{Conclusion}

This work demonstrates the potential of polyphenol-rich OMWW extract for 
use in hair care. Due to the positive influence of the substance on cell proliferation and release of the growth factor IGF-1 of the hair follicle dermal papilla cells, OMWW could contribute to improved and prolonged hair growth in vivo. In addition, its antioxidant capabilities could prevent oxidative stress and the formation of free radicals on the scalp and in the hair follicles. Consequently, OMWW would contribute to the maintenance of a healthy scalp and possibly prevent hair loss due to oxidative stress.

\section{Acknowledgements}

The authors would like to acknowledge the financial support by Gianni Lo Franco, Antonio Lo Franco and Bandino Lo Franco (Fattoria la Vialla, Italy; fattoria@lavialla.it) and the samples provided. We thank Prof. Dr. Adriana Albini, Department of Medicine and Surgery, University Milano-Bicocca, Milan, Italy and Scientific and Technology Pole, IRCCS MultiMedica, Milan, Italy for her scientific support of the project. We are grateful to Dres. Massimo and Daniele Pizzichini (Genelab srl, ENEA) for the phenol rich purified extract (OMWW extract, A009).

\section{Conflicts of Interest}

The authors declare no conflicts of interest.

\section{References}

[1] Cash, T.F. (1992) The Psychological Effects of Androgenetic Alopecia in Men. Journal of the American Academy of Dermatology, 26, 926-931. https://doi.org/10.1016/0190-9622(92)70134-2

[2] Cash, T.F., Price, V.H. and Savin, R.C. (1993) Psychological Effects of Androgenetic Alopecia on Women: Comparisons with Balding Men and with Female Control Subjects. Journal of the American Academy of Dermatology, 29, 568-575. https://doi.org/10.1016/0190-9622(93)70223-G

[3] Millar, S.E. (2002) Molecular Mechanisms Regulating Hair Follicle Development. Journal of Investigative Dermatology, 118, 216-225. https://doi.org/10.1046/j.0022-202x.2001.01670.x

[4] Ruszczak, Z. (2012) Hair Disorders and Alopecia. In: Elzouki, A.Y., Harfi H.A., Nazer H.M., Stapleton F.B., Oh W. and Whitley R.J., Eds., Textbook of Clinical Pediatrics, Springer, Berlin, Heidelberg, 1489-1508. https://doi.org/10.1007/978-3-642-02202-9_146

[5] Stenn, K.S. and Paus, R. (2001) Controls of Hair Follicle Cycling. Physiological Reviews, 81, 449-494. https://doi.org/10.1152/physrev.2001.81.1.449

[6] Dawber, R.P. (1997) Diseases of the Hair and Scalp. Wiley-Blackwell, Hoboken.

[7] Roh, C., Tao, Q., Photopoulos, C. and Lyle, S. (2005) In Vitro Differences between Keratinocyte Stem Cells and Transit-Amplifying Cells of the Human Hair Follicle. Journal of Investigative Dermatology, 125, 1099-1105. https://doi.org/10.1111/j.0022-202X.2005.23958.x

[8] Mistriotis, P. and Andreadis, S.T. (2013) Hair Follicle: A Novel Source of Multipotent Stem Cells for Tissue Engineering and Regenerative Medicine. Tissue Engineering Part B: Reviews, 19, 265-278. https://doi.org/10.1242/jcs.02793 
[9] Alonso, L. and Fuchs, E. (2006) The Hair Cycle. Journal of Cell Science, 119, 391-393. https://doi.org/10.1242/jcs.02793

[10] Paus, R. and Cotsarelis, G. (1999) The Biology of Hair Follicles. New England Journal of Medicine, 341, 491-497. https://doi.org/10.1056/NEJM199908123410706

[11] Balana, M.E., Charreau, H.E. and Leiros, G.J. (2015) Epidermal Stem Cells and Skin Tissue Engineering in Hair Follicle Regeneration. World Journal of Stem Cells, 7, 711-727. https://doi.org/10.4252/wjsc.v7.i4.711

[12] Rajendran, R.L., Gangadaran, P., Bak, S.S., Oh, J.M., Kalimuthu, S., Lee, H.W., et al. (2017) Extracellular Vesicles Derived from MSCs Activates Dermal Papilla Cell in Vitro and Promotes Hair Follicle Conversion from Telogen to Anagen in Mice. Scientific Reports, 7, Article No. 15560. https://doi.org/10.1038/s41598-017-15505-3

[13] Peus, D. and Pittelkow, M.R. (1996) Growth Factors in Hair Organ Development and the Hair Growth cycle. Dermatologic Clinics, 14, 559-572.

https://doi.org/10.1016/S0733-8635(05)70384-3

[14] Ben Amitai, D., Lurie, R. and Laron, Z. (2006) I-GF-1 Signalling Controls the Hair Growth Cycle and the Differentiation of Hair Shafts. Journal of Investigative Dermatology, 126, 2135. https://doi.org/10.1038/sj.jid.5700436

[15] Shimomura, Y. and Christiano, A.M. (2010) Biology and Genetics of Hair. Annual Review of Genomics and Human Genetics, 11, 109-132. https://doi.org/10.1146/annurev-genom-021610-131501

[16] Botchkarev, V.A. (2003) Stress and the Hair Follicle: Exploring the Connections. American Journal of Pathology, 162, 709-712. https://doi.org/10.1016/S0002-9440(10)63866-7

[17] Lolli, F., Pallotti, F., Rossi, A., Fortuna, M.C., Caro, G., Lenzi, A., et al. (2017) Androgenetic Alopecia: A Review. Endocrine, 57, 9-17. https://doi.org/10.1007/s12020-017-1280-y

[18] Tajima, M., Hamada, C., Arai, T., Miyazawa, M., Shibata, R. and Ishino, A. (2007) Characteristic Features of Japanese Women's Hair with Aging and with Progressing Hair Loss. Journal of Dermatological Science, 45, 93-103.

https://doi.org/10.1016/j.jdermsci.2006.10.011

[19] Camacho-Martinez, F.M. (2009) Hair Loss in Women. Seminars in Cutaneous Medicine and Surgery. https://doi.org/10.1016/j.sder.2009.01.001

[20] Schlupp, P., Schmidts, T.M., Pössl, A., Wildenhain, S., Lo Franco, G., Lo Franco, A., et al. (2019) Effects of a Phenol-Enriched Purified Extract from Olive Mill Wastewater on Skin Cells. Cosmetics, 6, Article No. 30. https://doi.org/10.3390/cosmetics6020030

[21] Kwon, O.S., Han, J.H., Yoo, H.G., Chung, J.H., Cho, K.H., Eun, H.C., et al. (2007) Human Hair Growth Enhancement in Vitro by Green Tea Epigallocatechin-3-Gallate (EGCG). Phytomedicine, 14, 551-555.

https://doi.org/10.1016/j.phymed.2006.09.009

[22] Riccio, G., Sommella, E., Badolati, N., Salviati, E., Bottone, S., Campiglia, P., et al. (2018) Annurca Apple Polyphenols Protect Murine Hair Follicles from Taxane Induced Dystrophy and Hijacks Polyunsaturated Fatty Acid Metabolism toward $\beta$-Oxidation. Nutrients, 10, Article No. 1808. https://doi.org/10.3390/nu10111808

[23] Rossi, T., Bassani, B., Gallo, C., Maramotti, S., Noonan, D.M., et al. (2015) Effect of a Purified Extract of Olive Mill Waste Water on Endothelial Cell Proliferation, Apoptosis, Migration and Capillary-Like Structure in Vitro and in Vivo. Journal of Bioanalysis and Biomedicine, 12, Article No. 6.

[24] Mosmann, T. (1983) Rapid Colorimetric Assay for Cellular Growth and Survival: 
Application to Proliferation and Cytotoxicity Assays. Journal of Immunological Methods, 65, 55-63. https://doi.org/10.1016/0022-1759(83)90303-4

[25] Yang, C.-C. and Cotsarelis, G. (2010) Review of Hair Follicle Dermal Cells. Journal of Dermatological Science, 57, 2-11. https://doi.org/10.1016/j.jdermsci.2009.11.005

[26] Driskell, R.R., Clavel, C., Rendl, M. and Watt, F.M. (2011) Hair Follicle Dermal Papilla Cells at a Glance. Journal of CELL Science, 124, 1179-1182. https://doi.org/10.1242/jcs.082446

[27] Shin, S.-H., Park, S.-Y., Kim, M.-K., Kim, J.-C. and Sung, Y.-K. (2011) Establishment and Characterization of an Immortalized Human Dermal Papilla Cell Line. BMB Reports, 44, 512-516. https://doi.org/10.5483/BMBRep.2011.44.8.512

[28] Kaufman, K.D. (1996) Androgen Metabolism as It Affects Hair Growth in Androgenetic Alopecia. Dermatologic Clinics, 14, 697-711. https://doi.org/10.1016/S0733-8635(05)70396-X

[29] Winiarska, A., Mandt, N., Kamp, H., Hossini, A., Seltmann, H., Zouboulis, C.C., et al. (2006) Effect of 5a-Dihydrotestosterone and Testosterone on Apoptosis in $\mathrm{Hu}$ man Dermal Papilla Cells. Skin Pharmacology and Physiology, 19, 311-321. https://doi.org/10.1159/000095251

[30] Lee, M.J., Cha, H.J., Lim, K.M., Lee, O.K., Bae, S., Kim, C.H., et al. (2015) Analysis of the MicroRNA Expression Profile of Normal Human Dermal Papilla Cells Treated with 5a-Dihydrotestosterone. Molecular Medicine Reports, 12, 1205-1212. https://doi.org/10.3892/mmr.2015.3478

[31] Shin, S., Kim, K., Lee, M.J., Lee, J., Choi, S., Kim, K.S., et al. (2016) Epigallocatechin Gallate-Mediated Alteration of the MicroRNA Expression Profile in $5 \alpha$-Dihydrotestosterone-Treated Human Dermal Papilla Cells. Annals of Dermatology, 28, 327-334.

[32] Fischer, T.W., Hipler, U.C. and Elsner, P. (2007) Effect of Caffeine and Testosterone on the Proliferation of Human Hair Follicles in Vitro. International Journal of Dermatology, 46, 27-35. https://doi.org/10.1111/j.1365-4632.2007.03119.x

[33] Fischer, T.W., et al. (2014) Differential Effects of Caffeine on Hair Shaft Elongation, Matrix and Outer Root Sheath Keratinocyte Proliferation, and Transforming Growth Factor-Beta2/Insulin-Like Growth Factor-1-Mediated Regulation of the Hair Cycle in Male and Female Human Hair Follicles in Vitro. British Journal of Dermatology, 171, 1031-1043. https://doi.org/10.1111/bjd.13114

[34] Herman, A. and Herman, A.P. (2013) Caffeine's Mechanisms of Action and Its Cosmetic Use. Skin Pharmacology and Physiology, 26, 8-14. https://doi.org/10.1159/000343174

[35] Zhuang, X.-S., Sun, W.-L. and Fan, W.-X. (2013) Mechanisms of caffeine Antiandrogenic on Human Dermal Papilla Cells in Vitro. Journal of Clinical Dermatology, 42, 137-141.

[36] Madaan, A., Verma, R., Singh, A.T. and Jaggi, M. (2018) Review of Hair Follicle Dermal Papilla Cells as in Vitro Screening Model for Hair Growth. International Journal of Cosmetic Science, 40, 429-450. https://doi.org/10.1111/ics.12489

[37] Shin, H., Cho, A.R., Kim, D.Y., Munkhbayer, S., Choi, S.J. and Jang, S. (2016) Enhancement of Human Hair Growth Using Ecklonia cava Polyphenols. Annals of Dermatology, 28, 15-21.

[38] Kiesewetter, F., Arai, A. and Schell, H. (1993) Sex Hormones and Antiandrogens Influence in Vitro Growth of Dermal Papilla Cells and Outer Root Sheath Keratinocytes of Human Hair Follicles. Journal of Investigative Dermatology, 101, 98S-105S. https://doi.org/10.1016/0022-202X(93)90508-F

[39] Wang, J.M. and Zhang, J.T. (2012) Progress in Relevant Growth Factors Promoting 
the Growth of Hair Follicle. American Journal of Animal and Veterinary Sciences, 7, 104-111. https://doi.org/10.3844/ajavsp.2012.104.111

[40] Tang, L., Bernardo, O., Bolduc, C., Lui, H., Madani, S. and Shapiro, J. (2003) The Expression of Insulin-Like Growth Factor 1 in Follicular Dermal Papillae Correlates with Therapeutic Efficacy of Finasteride in Androgenetic Alopecia. Journal of the American Academy of Dermatology, 49, 229-233. https://doi.org/10.1067/S0190-9622(03)00777-1

[41] Yano, K., Brown, L.F. and Detmar, M. (2001) Control of Hair Growth and Follicle Size by VEGF-Mediated Angiogenesis. Journal of Clinical Investigation, 107, 409-417. https://doi.org/10.1172/JCI11317

[42] Jones, J.I. and Clemmons, D.R. (1995) Insulin-Like Growth Factors and Their Binding Proteins: Biological Actions. Endocrine Reviews, 16, 3-34.

https://doi.org/10.1210/edrv-16-1-3

[43] Weger, N. and Schlake, T. (2005) Igf-I Signalling Controls the Hair Growth Cycle and the Differentiation of Hair Shafts. Journal of Investigative Dermatology, 125, 873-882. https://doi.org/10.1111/j.0022-202X.2005.23946.x

[44] Danilenko, D.M., Ring, B.D. and Pierce, G.F. (1996) Growth Factors and Cytokines in Hair Follicle Development and Cycling: Recent Insights from Animal Models and the Potentials for Clinical Therapy. Molecular Medicine Today, 2, 460-467. https://doi.org/10.1016/1357-4310(96)10045-9

[45] Zhao, J., Harada, N., Kurihara, H., Nakagata, N. and Okajima, K. (2011) Dietary Isoflavone Increases Insulin-Like Growth Factor-I Production, Thereby Promoting Hair Growth in Mice. The Journal of Nutritional Biochemistry, 22, 227-233. https://doi.org/10.1016/j.jnutbio.2010.01.008

[46] Zhao, J., Harada, N. and Okajima, K. (2011) Dihydrotestosterone Inhibits Hair Growth in Mice by Inhibiting Insulin-Like Growth Factor-I Production in Dermal Papillae. Growth Hormone \& IGF Research, 21, 260-267. https://doi.org/10.1016/j.ghir.2011.07.003

[47] Lachgar, S., Charveron, M., Sarraute, J., Mourard, M., Gall, Y. and Bonafe, J.L. (1999) In Vitro Main Pathways of Steroid Action in Cultured Hair Follicle Cells: Vascular Approach. Journal of Investigative Dermatology Symposium Proceedings, 4, 290-295. https://doi.org/10.1038/sj.jidsp.5640232

[48] Ozeki, M. and Tabata, Y. (2002) Promoted Growth of Murine Hair Follicles through Controlled Release of Vascular Endothelial Growth Factor. Biomaterials, 23, 2367-2373. https://doi.org/10.1016/S0142-9612(01)00372-6

[49] Liang, X., Bhattacharya, S., Bajaj, G., Guha, G., Wang, Z., Jang, H.-S., et al. (2012) Delayed Cutaneous Wound Healing and Aberrant Expression of Hair Follicle Stem Cell Markers in Mice Selectively Lacking Ctip2 in Epidermis. PLoS ONE, 7, Article ID: e29999. https://doi.org/10.1371/journal.pone.0029999

[50] Kim, S., Kim, S.N., Jeong, G., Hong, M.J., Lee, Y., Shin, S.H., et al. (2019) Efficacy of Caffeine in Promoting Hair Growth by Enhancing Intracellular Activity of Hair Follicles. Korea Journal of Cosmetic Science, 1, 11-18.

[51] Moskovitz, J., Yim, M.B. and Chock, P.B. (2002) Free Radicals and Disease. Archives of Biochemistry and Biophysics, 397, 354-359.

https://doi.org/10.1006/abbi.2001.2692

[52] Upton, J.H., Hannen, R.F., Bahta, A.W., Farjo, N., Farjo, B. and Philpott, M.P. (2015) Oxidative Stress-Associated Senescence in Dermal Papilla Cells of Men with Androgenetic Alopecia. Journal of Investigative Dermatology, 135, 1244-1252. https://doi.org/10.1038/jid.2015.28 
[53] Liu, S., Navarro, G. and Mauvais-Jarvis, F. (2010) Androgen Excess Produces Systemic Oxidative Stress and Predisposes to Beta-Cell Failure in Female Mice. PLoS $O N E$, 5, Article ID: e11302. https://doi.org/10.1371/journal.pone.0011302

[54] Sung, Y.K., Hwang, S.Y., Cha, S.Y., Kim, S.R., Park, S.Y., Kim, M.K., et al. (2006) The Hair Growth Promoting Effect of Ascorbic Acid 2-Phosphate, a Long-Acting Vitamin C Derivative. Journal of Dermatological Science, 41, 150-152.

https://doi.org/10.1016/j.jdermsci.2005.11.010 